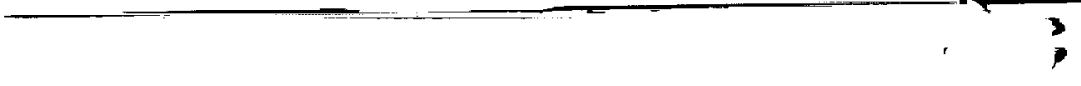

NASA Technical Memorandum 103199

\title{
An Analysis of Space Power System Masses
}

(NASA-TM-103199) AN ANALYSIS OF SPACE POWER SYSTEM MASSES (NASA) 3 P CSCL $21 \mathrm{H}$ N90-25184

Barbara H. Kenny

Sverdrup Technology, Inc.

Lewis Research Center Group

Brook Park, Ohio

and

Ronald C. Cull and M. David Kankam

Lewis Research Center

Cleveland, Ohio

Prepared for the

25th Intersociety Energy Conversion Engineering Conference

- cosponsored by the AIChE, ANS, SAE, ACS, AIAA, ASME, and IEEE

Reno, Nevada, August 12-17, 1990 
$\therefore \quad \therefore=-1$

$1+\cdots$

$\ldots+\cdots=$ 


\title{
AN ANALYSIS OF SPACE POWER SYSTEM MASSES
}

\author{
Barbara H. Kenny \\ Sverdrup Technology, Inc. \\ and \\ Ronald C. Cull and M. David Kankam \\ National Aeronautics and Space Administration \\ Lewis Research Center \\ Cleveland, Ohio 44135
}

\begin{abstract}
This paper analyzes various space electrical power system masses with particular emphasis on the power management and distribution (PMAD) portion. The electrical power system (EPS) is divided into functional blocks: source, interconnection, storage, Iransmission, distribution, system control and load. The PMAD subsystem is defined as all the blocks between the source, storage and load, plus the power conditioning equipment required for the source, storage and load. The EPS mass of a wide range of spacecratt is then classified as source, storage or PMAD and tabulated in a database. The intent of the database is to serve as a reference source for PMAD masses of existing and in-design spacecraft.
\end{abstract}

The PMAD masses in the database range from $40 \mathrm{~kg} / \mathrm{kw}$ to 183 $\mathrm{kg} / \mathrm{kw}$ across the spacecraft syslems studied. Factors influencing the power system mass are identilied. These include the tolal spacecraft power requirements, lotal amount of load capacily and physical size of the spacecraft. It is found a new "utility" class of power systems, represented by Space Station Freedom, is evolving.

\section{INTRODUCTION}

A typical space electrical power system (EPS) consists of a power generating source(s) storage (it necessary). power management and distribution (PMAD), and load(s). A survey of existing literalure shows that considerable inlormation exists about the source and storage portions of space power systems. Inlormation about the PMAD portion, on the olher hand, is scarce. PMAD subsystem mass inlormation is required when performing system Irade-off sludies for advanced missions. PMAD component masses are readily available, but using component mass alone in system studies is not accurale. Mass data on the PMAD subsystem as a whole is needed but difficult to find. Thus, the primary objective of this paper is to analyze various space electrical power systems to obtain PMAD subsystem masses.

\section{POWER MANAGEMENT AND DISTRIBUTION (PMAD)}

A broad delinition of PMAD is necessary lor the underslanding and documentation ol its masses lor diflerent types of spacecratt. The PMAD subsystem is defined here as pertorming all electrical power system functions other than generation and slorage. Thus, the PMAD subsyslem performs the lollowing functions: power conversion, conditioning, transmission and distribution, and power system control. This PMAD definition can be explained by an analogy with the terrestrial utility system which is schematically illustrated in Figure 1. In a terrestrial utility system, power is generated by multiple sources, such as nuclear and coal power plants, and transmitted over a transmission and distribution grid to multiple loads.

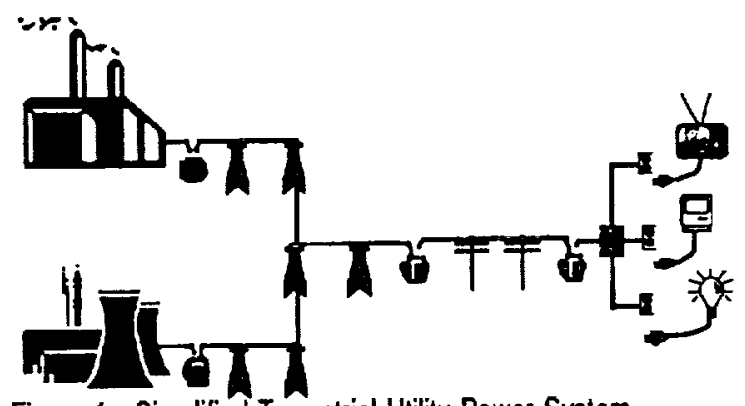

Figure 1 Simplified Terrestrial Utility Power System

The various utility components can be grouped according to their function. The power plant is the electric generating source for the system. Its heal source is converted to electricity by generalors typically rated between 14 and $22 \mathrm{kv}$ at $60 \mathrm{~Hz}$. The vollage is stepped up to transmission voltage levels, in the hundreds of kilovolts range. through transformers located just outside the generating station. The backbone of the utility, a flexible transmission grid, interconnects multiple sources and transmits to muttiple load locations. Subsequent power distribution is at stepped down voltage levels prior to distribution to load centers. Finally, the loads convert the electricity to the useful function desired by the consumer. Manned control centers tie the whole system logether and manage its operalion.

Figure 2 shows the functional groupings of the system and the portion defined by PMAD. The functional groupings are power generation, interconnection, transmission, distribution, loads, and system control. The PMAD boundary encompasses the interconnection, Iransmission, distribution and control center boxes. in also intersects a portion of the source and load boxes. The intersection of the PMAD boundary with the source and loads indicates that there is a PMAD function required within them. The Iransformers in the source boxes are associated with the generating station, yel they are performing a PMAD function. Likewise, at the load end, most loads do not use 120 volts ac, $60 \mathrm{hz}$ 
power directly. Some loads have inlernal conditioning. The computer, for example, has logic chips that operate on $+1-5$ volts dc which is derived from the supplied power. This internal conditioning done by the load is actually a PMAD function.

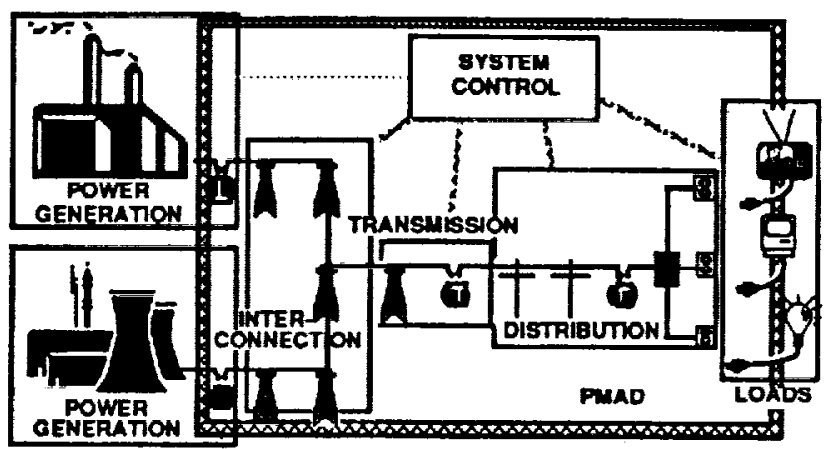

Figure 2 Functional Representation of Terrestrial Utility Power System

A similar functional block diagram of a generic electrical power system is shown in Figure 3. This basic block diagram captures the functions of a lerresirial, satellite, lunar base or Space Station Freedom (SSF) power system. The PMAD functions associaled with the source, load and storage are called power conditioning and conlrol (PC\&C).

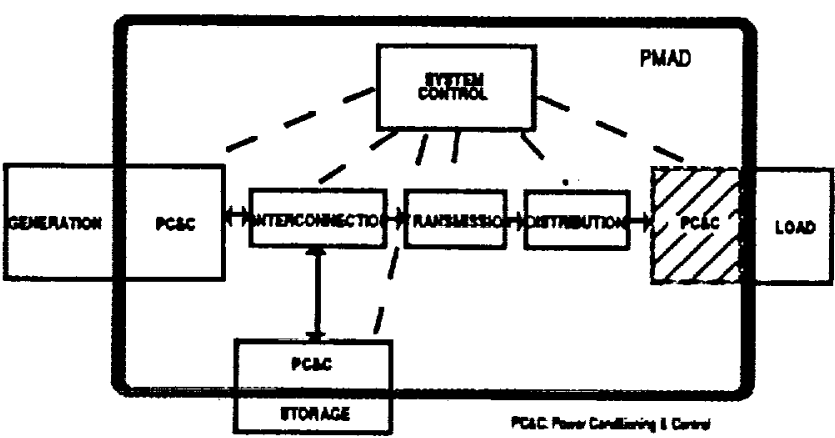

Figure 3 Electrical Power System Functional Block Diagram

In Figure 3 the power conditioning and conlrol (PC\&C) block associaled with the load is shaded. This is to indicale a "gray" area in the PMAD definition for space power systems. Technically, in terms of function, the equipment in the load PC\&C is PMAD and is shown within the PMAD boundary in Figure 3. However, practically, this equipment is almost always a user responsibility, lalling complelely in the load block and oulside the PMAD boundary. The dala base reflects this and does not include the load PC\&C in quoted PMAD masses. However, in future large power systems trade-off studies, the load PC\&C should be included in the PMAD mass estimates. This is based on the polential importance of the interaction between the PMAD design and the load PC\&C equipment for the total EPS optimization.

\section{BALANCE OF SYSTEM}

Electrical componenls require supporting components and systems to be able to function properly. In terrestrial power systems, such support takes the form of Iransmission lowers, cooling ponds and towers for the generating stalions, and other equipment without which the electrical power could nol be generated, transmitted or distributed. In space power systems, such support consists of thermal control to koep the electronics at the proper temperature, structural items such as booms to mount solar array panels or electrical equipment, and mechanisms such as the solar anay drive. Thus, the entire electrical power system mass should include not only the source, storage and PMAD, but also the support items necessary for proper EPS lunction.

"Balance of System" in the equation below captures the concept of the EPS suppor items:

EPS mass - Source mass + Storage mass+ "Balance of System" mass

"Balance of syslem" (BOS) is defined to include the PMAD subsystem and the thermal control, structures, mechanisms, elc. necessary for the power system to operate.

\section{DATABASE}

With PMAD delined, the question "What does PMAD weigh?" can be investigated. Information on various types of spacecratt was obtained, analyzed and compiled: JPL planetary spacecraft (Mariner R, Mariner C, Ranger Blk III, MV 67, MV 69, MM 71, MVM 73, VO 75, Voyager, Galileo, Magellan), orbiting spacecraft (COBE, Polar Platlorm), and several Space Station Freedom designs. The data is recorded using a standard spreadsheet program. Each spacecratt has its own spreadsheet with all the available dala about the spacecraft recorded there. The parameters of inlerest are then summarlzed in one master spreadsheel which is linked to all the individual ones.

At present, the master file parameters include spacecraft source, storage and PMAD masses, power levels, orbit paramelers, date ol launch, and length of life. Parameters for the masier file can be added or deleted as necessary with the corresponding links to the individual files adjusted. This makes the database flexible so additional data (volume, for example) can be added as it becomes available.

More detailed information about a particular spacecrat can be bund in the individual spreadsheets. The original data Irom a mass dala report is entered by spacecralt subsystem. Component mass data in EPS subsystems is also entered. The componenls are then classified as source, storage, or BOS based on the earlier definitions. BOS components are further classilied as PMAD, structures or thermal. The component masses are then reorganized and added together, based on their classification, 10 find the total PMAO, source, storage, and BOS masses. Spacecraft power data, if available, is also enlered in the spreadsheet. In summary, subsystem and component masses are entered as shown on the original mass dala reports [1-6], then classified and regrouped as necessary to contorm to the PMAD and $B O S$ definitions. 
Table 1 Summary of Spacocratt EPS Mass

\begin{tabular}{|c|c|c|c|c|c|c|c|c|c|}
\hline \begin{tabular}{|l|l} 
Spacecraft & N \\
\end{tabular} & \begin{tabular}{|l|} 
Mass \\
Accuracy*
\end{tabular} & $\begin{array}{l}\text { PMAD } \\
(\mathrm{kg} / \mathrm{kw})\end{array}$ & $\begin{array}{l}\text { Source } \\
(\mathrm{kg} / \mathrm{kW})\end{array}$ & $\begin{array}{l}\text { Storage } \\
(\mathrm{kg} / \mathrm{kw})\end{array}$ & $\begin{array}{l}\mathrm{BOS} \\
(\mathrm{kg} / \mathrm{kw})^{* *}\end{array}$ & \begin{tabular}{|l|} 
Peak \\
Power-kw \\
\end{tabular} & $\begin{array}{l}\text { Average } \\
\text { Power-kw }\end{array}$ & orbit $^{* * *}$ & $\begin{array}{l}\text { launch } \\
\text { year }\end{array}$ \\
\hline Polar Platform & $E$ & 70 & 69 & 67 & 102 & N/A & 6 & LEO & N/A \\
\hline \begin{tabular}{|l|} 
SSF-Current \\
Design
\end{tabular} & $E$ & 144 & 9 & 111 & 346 & 100 & 75 & LEO & 1996 \\
\hline \begin{tabular}{|l|} 
SSF-AC-DC \\
Design
\end{tabular} & $E$ & 183 & 67 & 101 & 405 & 100 & $65 A$ & LEO & 1996 \\
\hline \begin{tabular}{l|} 
SSF-- $20 \mathrm{kHz}$ \\
design
\end{tabular} & $E$ & 125 & 57 & 86 & 264 & 100 & 7.1 & LEO & 1996 \\
\hline Mariner R & A & 72 & 142 & 101 & N/A & .15 & N/A & $\mathbf{P}$ & 1962 \\
\hline Mariner $C$ & A & 73 & 151 & 62 & N/A & 25 & N/A & $\mathbf{P}$ & 1964 \\
\hline Ranger Blk III & A & 80 & 143 & 158 & N/A & .15 & N/A & $\mathbf{P}$ & 1965 \\
\hline MV 67 & A & 67 & 87 & 60 & N/A & 25 & N/A & $\mathbf{P}$ & 1967 \\
\hline MV 69 & A & 40 & 118 & 37 & N/A & .44 & N/A & $\mathbf{P}$ & 1969 \\
\hline MM71 & A & 43 & 133 & 02 & N/A & .48 & N/A & $\mathbf{P}$ & 1971 \\
\hline MVM 73 & A & 63 & 74 & 64 & N/A & .46 & N/A & $\mathbf{P}$ & 1973 \\
\hline VO 75 & A & 61 & 127 & 109 & NA & 6 & $N / A$ & $\mathbf{P}$ & 1975 \\
\hline Voyager & A & 51 & 234 & 0- RTG & N/A & .48 & N/A & $\mathbf{P}$ & 1977 \\
\hline Galileo & A & 7 & 196 & 0-RTG & 129 & 57 & N/A & $\mathbf{P}$ & 1989 \\
\hline COBE & A & 155 & 58 & 38 & 293 & 1.02 & .73 & LEO & 1989 \\
\hline Magellan & A & 114 & 44 & 113 & 295 & .64 & 55 & $\mathbf{P}$ & 1989 \\
\hline
\end{tabular}

'E = Estimated mass $\quad$ "* LEO = Low Earth Orbit

" $A=$ Actual mass

"NA = Not Available

** P = Planetary spacecraft 


\section{DATA ANALYSIS}

The data from the master spreadsheet is summarized in Table 1. The values shown are all dimensioned as $\mathrm{kg} / \mathrm{kw}$. That is, the mass of the subsystem divided by the total system power. This allows some comparison between various spacecratt. Comparisons must be made with caution, however, because it is otten difficult to determine the appropriate $\mathrm{kw}$ divisor. The generated power and load power both vary over the life of the system. The solar array output power changes over its life, the load power requirements vary, and some systems have peaking capability where they use power from both the solar array and the batteries for a short period. In COBE, for example, the power varies from 688.9 watts required by the load to 1020 watts available from the solar array at beginning of lile (BOL) [3]. Some systems quote an average power. For example, Magellan quotes a time-weighled average power" [6], and Space Station Freedom (SSF) quoles 'continuous power rating" $[1,2]$. The exact load power requirements were not available for some systems, so source specilications were used. For example, Galileo has a 568 walt radioisotope thermoelectric generator (RTG) at BOL [4]. Generally, when the inlormation is available, average power is used to oblain the $\mathrm{kg} / \mathrm{kw}$ dimension. This is due to the fact that this work is geared loward supporting luture system designs which are oflen specified with an average user power level. (Using average power may not be the best procedure, and allernatives are discussed in the Spacecraft Attributes section.)

The PMAD $\mathrm{kg} / \mathrm{kw}$ values in Table 1 range from 40 for a planetary probe to 183 (estimated) for an SSF design. The PMAD and BOS mass estimates for the three SSF designs include only Work Package 4 items, namely, only the equipment Irom the source to the entrance to the modules). PMAD equipment inside the modules is a Work Package 1 responsibility [8]. Therelore, the PMAD mass for the entire SSF, source to load, will be grealer than that shown in Table 1. In addition, the three SSF mass estimates are each taken at a difterent time, at a diflerent stage of design. Therefore, these mass estimates are not necessarily a good indicator of the "best" design.

\section{SPACECRAFT ATTRIBUTES}

\section{Space Uilitiv}

Some preliminary observations can be made aboul the causes of the wide range in PMAD masses. One of the first and most obvious observations is the difference between the various types of spacecratt. The planelary probes are small in size and have power capabilities ol less than $1 \mathrm{kw}$. Space Station Freedom, on the other hand, is large in size and rated at $75 \mathrm{kw}$. With its multiple sources (8 solar array paneis), multiple loads, and large physical size, the SSF power system is more like a terrestrial utility system than a traditional spacecraft power system.

In the typical earlier spacecraft (Figure 4), the most obvious PMAD elements are contained in the PC\&C blocks, either associaled with the source, storage or load. A source regulator and the battery charge and discharge regulators are all that are shown on a iypical spacecrat power system block diagram [7]. The other lunctional blocks, inlerconnection, transmission and dislribution, exisl, but are not as readily obvious as PMAD elemenls. For example, the cabling for the power system (a Iransmission or distribution element) is often grouped with other lypes of cabling (data handling, communication) on the mass data report [3]. This makes it dilficult even to account br power cable as part of the PMAD mass.

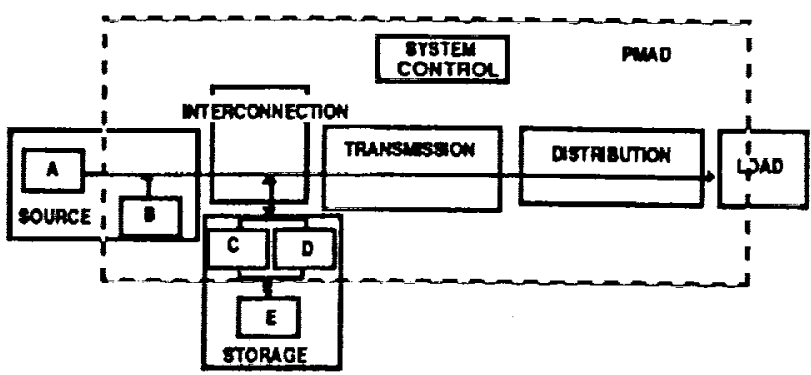

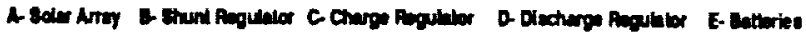

\section{Figure 4 Salellite EPS Block Diagram}

For the SSF, however, the interconnect, Iransmission and distribution blocks become very important. The SSF design musI interconnecl eight solar array panels and iwenty-four battery charge-discharge units. Then it must transmit the power 50 to 60 meters from the solar arrays to the main bus switching units (MBSUs). Finally, the power must be distributed to many users in many locations. As a result, the transmission and distribution blocks account for $60 \%$ of the PMAD mass (Figure 5). Transmission includes the four MBSUs, and PMAD cabling outboard of the alpha gimbal. Distribution includes the PMAD cabling inboard of the alpha gimbal, the thinty-two DC 10 DC converter units (DDCUs) for the modules, nodes and pallels, and the remole power controllers (RPCs) which will be installed in the modules and nodes.

There are other new leatures of the SSF which add requirements and mass to the PMAD subsystem. The SSF EPS is required to grow to a higher power level. It must be maintainable over a long life ( 30 years). Finally, it must be adaptable to many different users during that time.

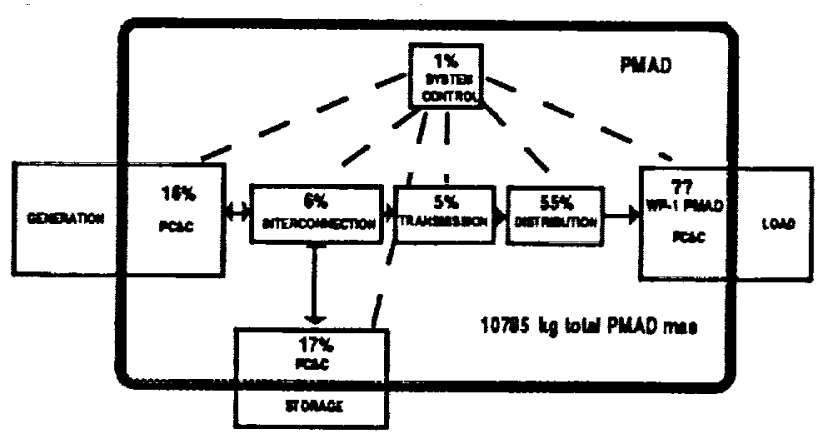

Figure 5 SSF EPS Block Diagram and PMAD masses

\section{Load Capacity}

Another feature of the SSF electrical power system is the physical availability of power to many places on the station. Many users can be connected 10 the power system, but only an average of $75 \mathrm{kw}$ worth of load may operate al any given time. This arrangement of sharing the power saves mass in the power system as a whole. At the load end, though, there is enough remole power controller (RPC) capability 10 connect approximately $2 \mathrm{Mw}$ worth of loads [2]. By loads sharing power, the source and storage can be sized to provide much less than the load capacity of $2 \mathrm{Mw}$. Although mass is saved in the power system in the source and slorage areas, PMAD becomes quite large to provide the wiring and components lor 2 Mw ol loads. 


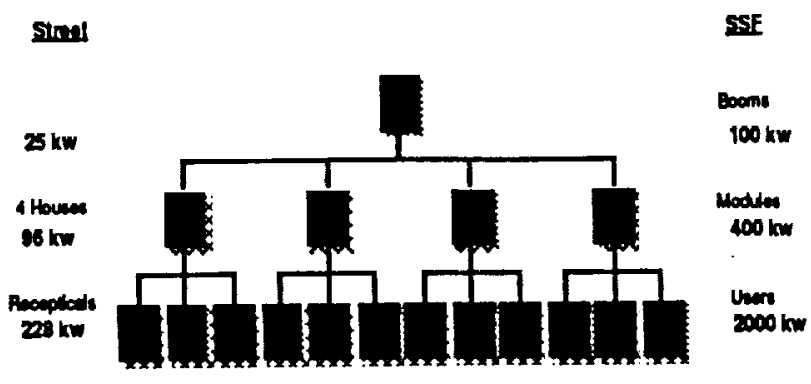

Figure 6 Power Tree

This is not unique to the SSF and may be best illustrated by use of another ferrestrial analogy, a residential street power distribution system (Figure 6). Typically, a 25 kva Iranslormer provides $120 / 240$ volt power to muttiple houses, four in this example. At the entry point to each house there is a main circuit breaker, typically rated at 100 amps. That gives $24 \mathrm{kw}$ available at each house, or $96 \mathrm{kw}$ available for all lour houses. II all the circuit breakers or fuses in the main panel for each house were added logelher, there would be more power than the main breaker rating, say $57 \mathrm{kw}$ in this example. For all lour houses, that would be $228 \mathrm{kw}$ worth of load capacity. In other words, athough the streel transformer can provide only 25 kva worth of power, each of the houses are provided with enough PMAD equipment for $57 \mathrm{kw}$, or $228 \mathrm{kw}$ total. For the SSF, the solar arrays and batteries are sized for a peak power output of $100 \mathrm{kw}$. There are a lotal of $400 \mathrm{kw}$ of $D C$ to DC converter units (DDCUs) provided at all the nodes and modules and user distribution points. There are $2 \mathrm{Mw}$ of remole power controllers (RPCs) al the user end.

Nol all of the user capacity is built into the SSF for convenience and flexibility. Some of the RPCs and DDCUs are required for redundancy. Some are there for future growth of SSF. If that occurs, more source capability will be added, so that more loads could operale at once with the existing PMAD. Finally, some of the $2 \mathrm{Mw}$ of RPCs is due to packaging constrainis. An RPC module is designed with one 130 amp RPC, or two 50 amp RPCs, or four 25 amp RPCs, or eight 10 amp RPCs. Hence, even il only three 10 amp RPCs are required in one particular location, eight will be installed since the packaging comes in that form.

Whatever the reasons, the idea of a large "load capacity" seems to be new with the SSF. From discussions with JPL designers and a COBE engineer, their spacecrat basically have the same load as source power. They indicaled that perhaps up to twice as much load capacity versus source may occur in some cases, but nowhere near the 20:1 load capacity to source ratio found in the SSF. This idea of connectable load warrants further investigation as more data is gathered on other salelites. A large connectable load lo source ratio may be a generic leature of large manned power systems, such as the SSF and others planned for the moon or Mars.

In estimaling the PMAD masses for tuture large power systems, bad capacity must be considered. As stated earlier under the "Database" section, it is often dilficult to determine what $\mathrm{kw}$ value to use as the mass divisor to find a $\mathrm{kg} / \mathrm{kW}$ value for the PMAD subsystem. It may be more accurate to divide the power system up into sections based on the amount of power each section is required to handle, then estimate each seclion's mass based on its kw raling. For example, in Figure 5, the first lovel of the system from the solar arrays and batteries to the inlerconnection, would be raled at $100 \mathrm{kw}$, the peak power. The next level would be from the interconnection block through the transmission block to the $D C$ to $D C$ converter units (DDCUs) in the conversion block. This level would be rated at $400 \mathrm{kw}$ since this power level is the lotal capability of the DDCUs and associated wiring. The user level of the system would be the remainder ol the system, Irom the output of the DDCUs in the distribution block to the load. The user level would be raled at $2 \mathrm{Mw}$, the amount of load capacity. A PMAD $\mathrm{kg} / \mathrm{kw}$ value could be used for each section based on the items in the section. Such items may indude the RPCs, or RPCs plus cabling and converters, or whatever happens to be in a particular section. The corresponding $\mathrm{kw}$ value would be used to determine the PMAD $\mathrm{kg} / \mathrm{kw}$ mass. Finally, a summation of the masses of all the sections would yield the total mass. This method would be more accurate than just using one overall PMAD $\mathrm{kg} / \mathrm{kw}$ value and mulliplying it by the average required power.

\section{Balance of System}

In the SSF, the BOS mass is significant. In the current design, the BOS is $346 \mathrm{~kg} / \mathrm{kW}$, and less than half of that is the PMAD subsyslem. The rest of the mass is power system support (Figure 7 ). The amount of support equipment required appears to increase with the power level of space power syslems. Hence, it is anticipated that BOS, rather than PMAD alone, will be important for consideration. System trade-off sludies may show that the lightest PMAD for a given application is not neccessarily the lightest BOS or, in lurn, the lightest EPS.

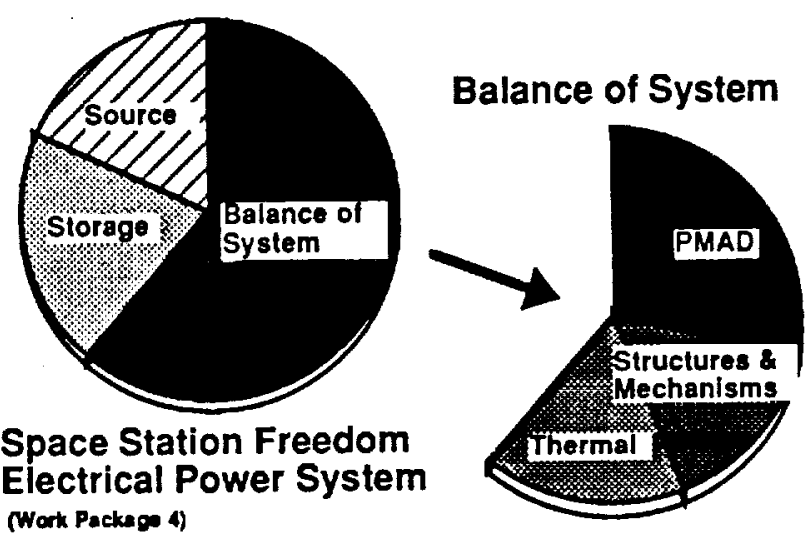

Total Mass $=41350 \mathrm{~kg}$

Figure 7 Space Station Freedom Balance of System

\section{Bedundancy}

Another teature of the SSF is redundancy. Man-rated syslems must have a certain level of reliability which can be achieved by the use of redundant components. However, redundancy adds mass to the PMAD subsystem. In one of the eartier SSF designs, there were eight main inverter units (MIU) specilied. Each unit was rated at $25 \mathrm{~kW}$ and weighed approximately $93 \mathrm{~kg}$ [1]. That gives a component unit mass of $3.72 \mathrm{~kg} / \mathrm{kw}$. However, there were eight of them specified for a $75 \mathrm{kw}$ load. Therelore, the total system MIU mass was $(8 \times 93) / 75=10 \mathrm{~kg} / \mathrm{kw}$.

\section{CONCLUSIONS}

EPS mass data Irom several spacecratt has been obtained, evalualed and entered in a database. An analysis of the PMAD masses in the database leads to the following conclusions: 
1. PMAD mass is nol insignificant, the smallest value being $40 \mathrm{~kg} / \mathrm{kw}$.

2. SSF data shows that a large distribuled utility-like power system is evolving. The interconnection, Iransmission and distribution blocks are much more significant than in a typical low power spacecratt.

3. The balance of system (BOS) is becoming more importanl as the power of the system increases. BOS is almost twothirds of the Space Station Freedom EPS mass. PMAD is only $50 \%$ of the BOS. The rest of the BOS mass is composed of thermal control, structures, and mochanisms.

4. SSF has a large load capacity compared 10 typical low power spacecrath. This will also probably be a teature of any high power system with growth requirements and a large number and diversity of loads.

5. Man-raled reliability requiremenls achieved through redundancy contribules significantly to PMAD masses.

In the tuture, the database will be expanded. Power system masses of various types of spacecraft will conlinue lo be added as the data becomes available. Additionally, other parameters such as life cycle cost, volume and efficiency will be added. This work is being undertaken to better understand how new lechnology can improve future space electrical power systems.

\section{REFERENCES}

[1] Level II Systems Enoineerine \& Inlegration Supoort: EPS Perlormance and Physical Properties Documentation Rockwell International Corporation, Rocketdyne Division. Rockwell Document Number RI/RD89-608, April 28, 1989.

[2] Power System Description Document Rockwell International Corporation, Rocketdyne Division. Rockwell Document Number RI/RD88-633, February 13, 1990.

[3] COBEIDelia Mass Dala Report, Goddard Space Flight Center, May 1989.

[4] Galilee Spacecratt Mass Report and Equioment List: Issue :39 Jet Propulsion Laboratory Interollice Memorandum Number 313389-501, Seplember 1, 1989.

[5] Jet Propulsion Laboratory in-house data on planetary spacecratt, compiled by the Power Electronics Group, November, 1989.

[6] Maoellan Mass Dala Report Documeèni Number VRM SE-021. 076, Seplember, 1988.

77 Chetly, P. R. K. Satellite Technology and lis Apolications, Tab Books, Inc., Pennsylvania, 1988. p. 114.

[B] Soace Station Program Definition and Requirements, Section 2: Brooram Management Requirements. Part 2: Work Breakdown Structure.

Document SSP 30,000, Revision D, March 15, 1989.

This work was supported by the NASA Lewis Research Center under contract NAS3-25266 with Ronald C. Cull as monitor. 


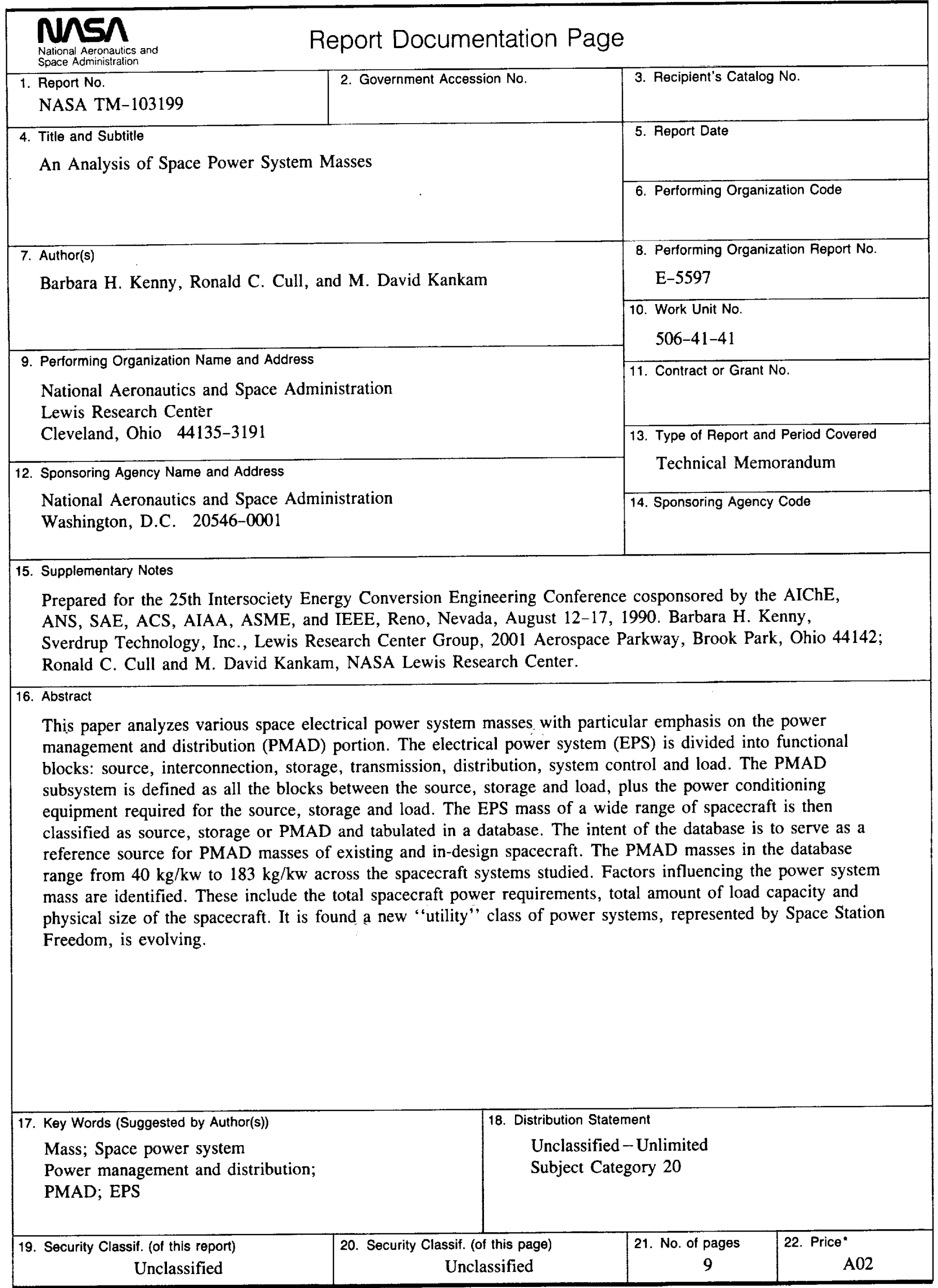


